\title{
Mekanistik ampirik esnek üstyapı tasarım modellerinin tabaka kalınlık ve rijitlik oranlarına bağlı olarak karşılaştırılması
}

\author{
Comparison of mechanistic empirical flexible pavement design models based on layer \\ thickness and stiffness ratios
}

\author{
Murat BOSTANCIOĞLU* \\ ${ }^{1}$ Sivas Cumhuriyet Üniversitesi, Mühendislik Fakültesi, İnşaat Mühendisliği Bölümü, 58140 Sivas
}

• Geliş tarihi / Received: 24.07.2020 • Düzeltilerek geliş tarihi / Received in revised form: 16.11 .2020 • Kabul tarihi / Accepted: 22.11 .2020

\section{$\ddot{O} z$}

Esnek üstyapıların tasarımında kullanılan mekanistik-ampirik yöntemlerde, trafik yükü ve çevresel etkiler altındaki kesitin mekanik tepkileri belirlenerek elde edilen bu değerler ampirik transfer denklemleri ile yol ömrü değerlerine dönüştürülmektedir. Farklı kuruluşlar tarafından önerilen ampirik modellerde dikkate alınan iki temel bozulma tipi yorulma ve tekerlek izidir. Bu iki bozulma tipine göre literatürde önerilen çok sayıda yol ömrü modeli bulunmakta ve bu modeller birbirlerinden önemli ölçüde farklı katsayılar içermektedir. Aynı kuruma ait yorulma ve tekerlek izi modelleri ile yapılan analizlerde dahi elde edilen yol ömrü değerleri birbirlerinden önemli ölçüde farklılık göstermektedir. Bu çalışmada seçilen geleneksel bir üstyapı kesiti için farklı ampirik modeller ile yol ömrü analizleri yapılmıştır. Yüzey ve temel tabakasının değişen rijitlik ve kalınlık oranlarına bağlı olarak transfer denklemleri birbirleri ile karşılaştırılmıştır. Elde edilen sonuçlar tüm kuruluşlar için tekerlek izi modelleri ile hesaplanan yol ömrü değerlerinin yorulma modelleri ile hesaplanan değerlerden fazla olduğunu göstermektedir. Temel tabakası rijitliğinin, yüzey tabakası rijitliğine kıyasla azalması durumunda farklı modellerden elde edilen sonuçlar birbirlerine yaklaşmaktadır. Yüzey tabakası kalınlığının temel tabakası kalınlığına kıyasla artması durumunda ise modellerin birbirlerinden önemli ölçüde farklı sonuçlar verdiği tespit edilmiştir.

Anahtar kelimeler: Kaplama ömrü, Mekanistik-ampirik tasarım, Tekerlek izi, Transfer modelleri, Yorulma

\begin{abstract}
In mechanistic-empirical methods used in the design of flexible pavements, the mechanical responses of the cross-section under traffic load and environmental influences are determined and these values are converted into pavement life values with empirical transfer equations. The two main types of distress considered in empirical models recommended by different organizations are fatigue and rutting. According to these two distress types, there are many pavement life models proposed in the literature and these models contain significantly different coefficients. Even in the analyzes made with the same institution's fatigue and rutting models, the pavement life values differ significantly from each other. In this study, pavement life analyzes were performed with different empirical models for a traditional pavement cross-section. Transfer equations are compared with each other depending on the changing stiffness and thickness ratios of the surface and base layer. The results obtained show that the pavement life values calculated with rutting models for all organizations are higher than the values calculated with fatigue models. If the base layer stiffness decreases compared to the surface layer stiffness, the results obtained from different models converge. In case the surface layer thickness increases compared to the base layer thickness, it is determined that the models give significantly different results from each other.
\end{abstract}

Keywords: Pavement life, Mechanistic-empirical design, Rutting, Transfer models, Fatigue

\footnotetext{
* Murat BOSTANCIOĞLU; bostancioglu@ cumhuriyet.edu.tr; Tel: (0346) 219 10 10-2226; orcid.org/0000-0001-6820-2213
} 


\section{Giriş}

Trafik yükü ve çevresel etkiler altında yol üstyapılarında, tekerlek izi ve yorulma gibi bir takım bozulma ve deformasyonlar meydana gelmekte ve yolun servis ömrü kısalmaktadır. Kaplamada meydana gelen deformasyonlar, kaplamanın bu yük ve etkilere gösterdiği gerilme, birim şekil değiştirme ve yer değiştirme (deplasman) tepkileri ile tanımlanmaktadır. Kaplamada oluşan tepkilerin belirli bir sınır değeri aşmaması için gerekli tabaka kalınlıklarının ve üstyapı kesitinin belirlenmesi ise üstyapı tasarımı olarak tanımlanabilir (Huang, 2004; Tunç, 2007; Chen, 2009). Üstyap1 alanında çalışan farklı kuruluşların önerdiği farklı üstyap1 tasarım yöntemleri mevcuttur. Tabaka kalınlığı hesabında Kaliforniya taşıma gücü oranı (CBR) değerinin kullanıldığı ampirik yöntem, Terzaghi taşıma gücü formülasyonun kullanıldığı kayma göçmesi sınır yöntemi, Burmister'ın iki tabaka teorisinin kullanıldığı deplasman sınır yöntemi, arazi deneylerinden elde edilen regresyon denklemlerinin kullanıldığı AASHTO yöntemi, tasarımda kullanılan bu yöntemlere örnek olarak verilebilir (Huang, 2004; Tunç, 2004; Hafeez vd., 2017). AASHTO yönteminin 1993 y1lında güncellenen versiyonu, ülkemiz karayolları üstyapı dizaynında da tercih edilen regresyon tabanlı ampirik bir yöntemdir (Sağlık ve Güngör, 2008). AASHTO yönteminde kullanılan tasarım denklemleri 1958-1960 yılları arasında Ottowa, Illinois'te yapılan yol testlerine bağlı olarak ortaya koyulmuştur. $\mathrm{Bu}$ yol testleri belirli bir coğrafi lokasyonda, sınırlı sayıda rijit ve esnek üstyap1 kesitinde ve sinırlı sayıda trafik yükleme tipinde yapılmıştır (Huang, 2004; Aguib, 2013; Lu vd., 2014). Buna göre türetilen ampirik denklemlerin yalnızca Illinois test parkurundaki koşulları tamamen yansıttığı söylenebilir (Mashayekhi vd., 2011; Lu vd., 2014). Ampirik AASHTO yönteminin bu kısıtlamalarını ortadan kaldırmak amacıyla son yıllarda araştırmacılar tarafindan mekanistik-ampirik (M-A) yöntemler üzerinde sıklıkla çalışılmaktadır (Hadi ve Bodhinayake, 2003; Abd Alla, 2006; Yoo vd., 2006; Mashayekhi vd., 2011; Mokhtari ve Nejad, 2012; Ahmed ve Erlingsson, 2016; Hafeez vd., 2017). Ampirik yöntemlerin aksine, M-A yöntemler araç ve yükleme, malzeme, imalat, tasarım parametrelerindeki değişime ve gelişen bilgisayar teknolojisine uyumlu olarak güncellenebilir niteliktedir (Mashayekhi vd., 2011). M-A yöntemlerin mekanistik aşamasında, matematiksel modeller ile kaplama performans kriterleri veya kaplama mekanik tepkileri (gerilme, deplasman, birim şekil değiştirme) hesaplanmakta, ampirik aşamasında ise bu mekanik tepki değerleri ampirik transfer denklemleri ile kaplamada meydana gelen yorulma ve tekerlek izi gibi deformasyonlar ile ilişkilendirilmektedir (Carvalho ve Schwartz, 2006; Mashayekhi vd., 2011; Behiry, 2012; Mousa vd., 2015). Kaplama analizinde yüke bağlı deformasyonların ilişkili olduğu iki kritik mekanik tepki, asfalt tabakasi altında meydana gelen yatay çekme birim şekil değiştirmeleri $\left(\varepsilon_{\mathrm{r}}\right)$ ve taban zemini üzerinde meydana gelen düşey basınç birim şekil değiştirmeleri $\left(\varepsilon_{\mathrm{v}}\right)$ olarak bildirilmiştir (Behiry, 2012; Muniandy vd., 2013). $\varepsilon_{\mathrm{r}}$ değerinin aşırı olması durumunda asfalt tabakasında çatlaklar meydana gelmekte ve kaplama yorulmaya bağlı olarak bozulmakta, $\varepsilon_{\mathrm{v}}$ değeri aşırı olduğunda ise taban zemininde kalıcı deformasyonlar meydana gelmekte ve kaplama tekerlek izine bağlı olarak bozulmaktadır (Adhikari vd., 2009; Behiry, 2012; Ekwulo ve Eme, 2009, 2013; Mousa vd., 2015). Bu iki kritik mekanik tepkiye bağlı olarak geliştirilmiş çok sayıda transfer denklemi ve yorulma/tekerlek izi modeli bulunmaktadır. Yorulma ve tekerlek izi modellerine ait genel denklemler Eşitlik 1 ve 2'de (Behiry, 2012; Muniandy et al., 2013), modellerde kullanılan katsayılar (f1-f5) Tablo 1'de verilmiştir.

$$
\begin{aligned}
& N_{f}=f 1 \varepsilon_{r}^{-f 2} E_{y \ddot{u} z e y}{ }^{-f 3} \\
& N_{r}=f 4\left(\varepsilon_{v}\right)^{-f 5}
\end{aligned}
$$

Burada, $\mathrm{N}_{\mathrm{f}}$ yorulmaya bağlı bozulma için gerekli yük tekrar sayısını, $\mathrm{N}_{\mathrm{r}}$ tekerlek izine bağlı bozulma için gerekli yük tekrar sayısını, Eyüzey yüzey tabakasının elastisite modülünü (psi) belirtmektedir.

Tablo 1. Farklı kuruluşlara ait model katsayıları (Behiry, 2012; Muniandy vd., 2013)

\begin{tabular}{ccccccccc}
\hline & AI & Shell & USACE & BRRC & TRRL & FHWA & ILLINOIS & ARE \\
\hline f1 & 0.0795 & 0.0685 & 497.156 & $4.92 \mathrm{E}-14$ & $1.66 \mathrm{E}-10$ & 0.1001 & $5.00 \mathrm{E}-06$ & $4.88 \mathrm{E}-01$ \\
f2 & 3.291 & 5.671 & 5 & 4.76 & 4.32 & 3.565 & 3 & 3.0312 \\
f3 & 0.854 & 2.363 & 2.66 & 0 & 0 & 1.474 & 0 & 0.6529 \\
$\mathbf{f 4}$ & $1.37 \mathrm{E}-09$ & $6.15 \mathrm{E}-07$ & $1.81 \mathrm{E}-15$ & $3.05 \mathrm{E}-09$ & $1.13 \mathrm{E}-06$ & --- & --- & --- \\
f5 & 4.477 & 4 & 6.527 & 4.35 & 3.75 & --- & --- & --- \\
\hline
\end{tabular}

AI: Asfalt Enstitüsü, USACE: ABD Ordusu Mühendisler Birliği, BRRC: Belçika Yol Araştırma Merkezi, TRRL: Ulaşım ve Yol Araştırma Laboratuarı, FHWA: Federal Karayolu İdaresi, ARE: Austin Araştırma Mühendisleri 
Tablo 1'de görüldüğü gibi farklı kuruluşlara ait model katsayıları birbirlerinden oldukça farklı olup bu modeller ile hesaplanan yol ömrü değerleri de birbirlerinden oldukça farklı sonuçlar vermektedir.

Mevcut çalışmanın amacı, belirlenen geleneksel bir üstyapı kesiti için M-A yöntemlerde kullanılan transfer modellerinin, aynı yükleme koşulları altında hesaplanan yol ömrü değerlerine bağlı olarak karşılaştırılması ve değişen tabaka kalınlığ ve tabaka rijitlik oranlarına bağlı olarak yöntemlerin hassasiyet analizlerinin yapılmasıdır. Çalışma, Türkiye Karayolları Genel Müdürlüğü Esnek Üstyapılar Projelendirme Rehberinde (EÜPR) tanımlanan farklı kesit tipleri için M-A yöntem modellerinin uygulanması ve değişen tasarım parametrelerine bağlı olarak kıyaslamalı analizlerin yapılmasi anlamında orijinal ve literatüre katkı sağlayacak niteliktedir.

\section{Materyal ve yöntem}

Çalışmada alttemel, temel ve bitümlü sıcak karışım (BSK) yüzey tabakasından oluşan geleneksel bir üstyap1 kesiti seçilmiştir (Şekil 1). Tabaka kalınlıkları z ekseni üzerinde tanımlanmıştır. Poisson oranı değerleri (v) tüm tabakalar için 0.35 alınmıştır (Hadi ve Bodhinayake, 2003; Huang, 2004; Ahmed ve Erlingsson, 2016; Sarkar, 2016).
Mekanik analizlerde kullanılmak üzere tabaka elastisite modüllerinin belirlenmesi için EÜPR'den (Sağlık ve Güngör, 2008) faydalanılmıştır. EÜPR'de BSK tabakası için izafi mukavemet katsayıları, aşınma, binder ve bitümlü temel tabakaları için sırasıyla $0.42-0.40$ ve 0.36 olarak belirtilmiştir. Bu değerler Huang (2004) tarafından önerilen grafiğe (Şekil 2) göre dönüştürüldüğünde BSK tabakası için elastisite modülünün ortalama değeri (E1) $2393 \mathrm{MPa}$ olarak hesaplanmıştır. Temel tabakası için önerilen izafi mukavemet katsayıları, çimento bağlayıcılı granüler temel için 0.23 , plent-miks temel için 0.15 ve granüler temel için 0.14'tür (Sağl1k ve Güngör, 2008). Alttemel izafi mukavemet katsayısı ise kırmataş alttemel için 0.13 olarak önerilmektedir. Temel tabakası izafi mukavemet katsayıları Eşitlik 3, alttemel tabakası izafi mukavemet katsayısı ise Eşitlik 4 ile (Huang, 2004) tabaka elastisite modüllerine dönüştürülmüş ve elde edilen değerler Tablo 2'de verilmiştir.

$$
\begin{aligned}
& a_{\text {temel }}=0.249 \times \log \left(E_{\text {temel }}\right)-0.977 \\
& a_{\text {alt temel }}=0.227 x \log \left(E_{\text {alt temel }}\right)-0.839
\end{aligned}
$$

Eşitliklerde $a_{\text {temel }}$ ve aaltemel sirasiyla temel ve alttemel tabakalarının izafi mukavemet katsayılarını, $E_{\text {temel }}$ ve $E_{\text {alttemel }}$ ise sirasiyla temel ve alttemel tabakalarının elastisite modülü değerlerini (psi) belirtmektedir.

Tablo 2. Hesaplanan tabaka elastisite modülü değerleri

\begin{tabular}{lcc}
\hline \multicolumn{1}{c}{ Tabaka adı } & İzafi mukavemet katsayısı (ai) & Elastisite modülü (MPa) \\
\hline Çimento bağlayıcılı granüler temel & 0.23 & 485 \\
Plent-miks temel & 0.15 & 232 \\
Granüler temel & 0.14 & 211 \\
\hline Kırmataş alttemel & 0.13 & 128.0 \\
\hline
\end{tabular}

Tablo 2'de verilen değerler dikkate alındığında BSK tabakası elastisite modülü değeri (E1) ile temel tabakas1 elastisite modülü değerleri (E2) arasındaki oranların (E1/E2) 5 ile 11 arasinda değiştiği görülmektedir (2393/485.2 ve 2393/211.1). Buna göre M-A modeller arasındaki karş1laştırmalar, E1/E2 oranının 5 ile 11 arasında olduğu 7 farklı değer için çalışılmıştır. Analizlerin taban zeminine bağl hassasiyetini değerlendirmek amaciyla taban zemini elastisite modülü $\left(\mathrm{E}_{\text {taban }}\right) 66$, 87 ve $110 \mathrm{MPa}$ olmak üzere 3 farklı değerde kullanılmıştır.

Analiz kesitlerinin tabaka kalınlıkları belirlenirken EÜPR'de 3 farklı güvenilirlik değeri (\%70-85 ve 95) ve farklı trafik kategorileri için önerilen 37 farklı kesitin kalınlık değerleri referans alınmıştır (Sağlik ve Güngör, 2008). Bu 37 kesitten 36'sinda
BSK tabakası kalınlığı 19-34 cm arasında değişirken temel tabakası kalınlığı 35 kesit için 20 $\mathrm{cm}$ olarak tavsiye edilmiştir. $\mathrm{Bu}$ değerlere göre BSK tabakası kalınlığının (H1) temel tabakası kalınlığına (H2) oran1 1.0 ile 1.7 (19/20 ve 34/20) arasında değiştirilerek analizler yapılmıştır. Alttemel tabakası kalınlığ (H3) ise sabit ve $20 \mathrm{~cm}$ olarak dikkate alınmıştır.

Kesit üzerindeki tekerlek yükü $80 \mathrm{kN}$ (8.2 ton) olarak belirlenmiş (Hadi ve Bodhinayake, 2003; Huang, 2004; Sağlık ve Güngör, 2008) ve bu yük akstaki tekil tekerleklere eşit olarak dağıtılmıştır. Tekerlek temas alanı dairesel kabul edilmiştir (Hafeez vd., 2017). Tekerlek iç basıncı $700 \mathrm{kPa}$ (Hadi ve Bodhinayake, 2003), ve $40 \mathrm{kN}$ yük altında bu iç basıncı sağlayan temas yarıçapı (CR) $13.5 \mathrm{~cm}$ olarak hesaplanmış ve analizlerde kullanılmıştır. 


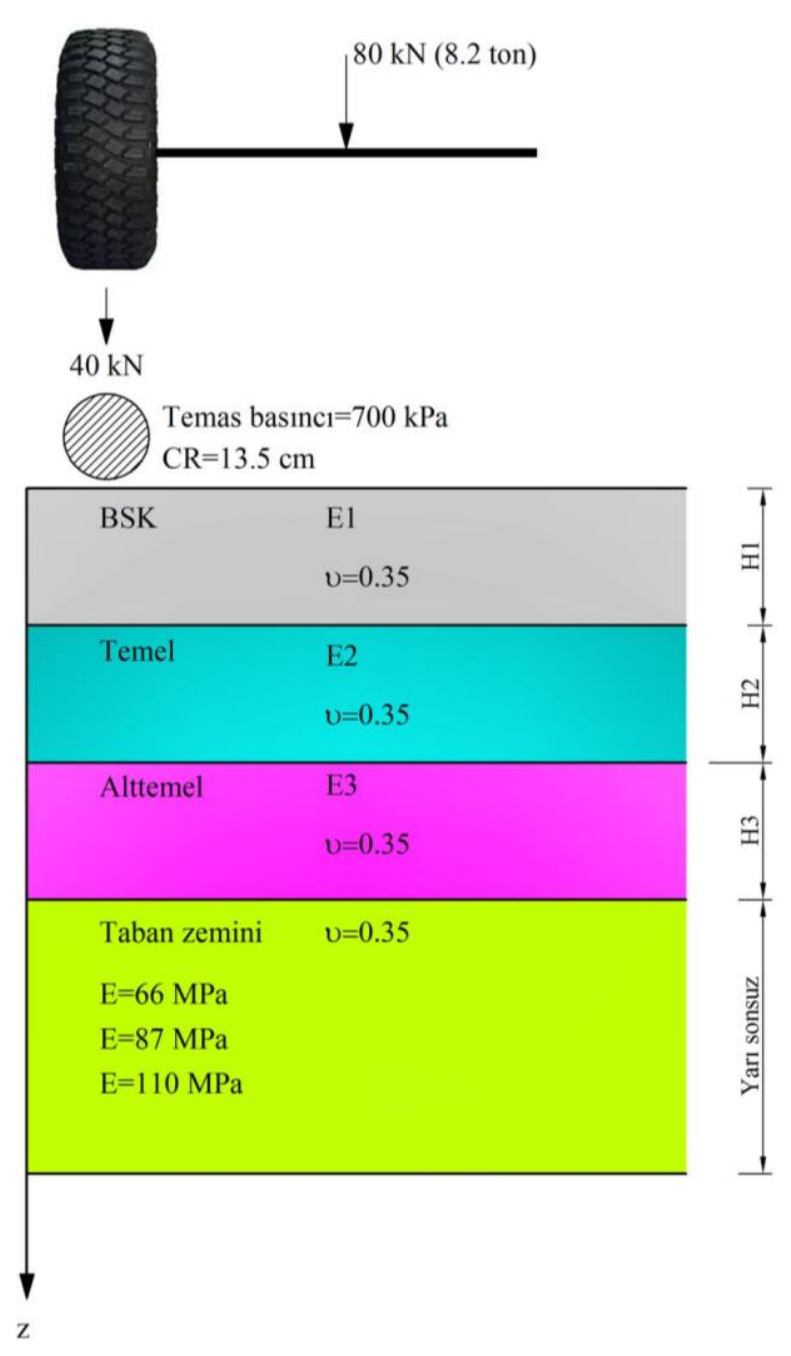

Şekil 1. Model geometrisi

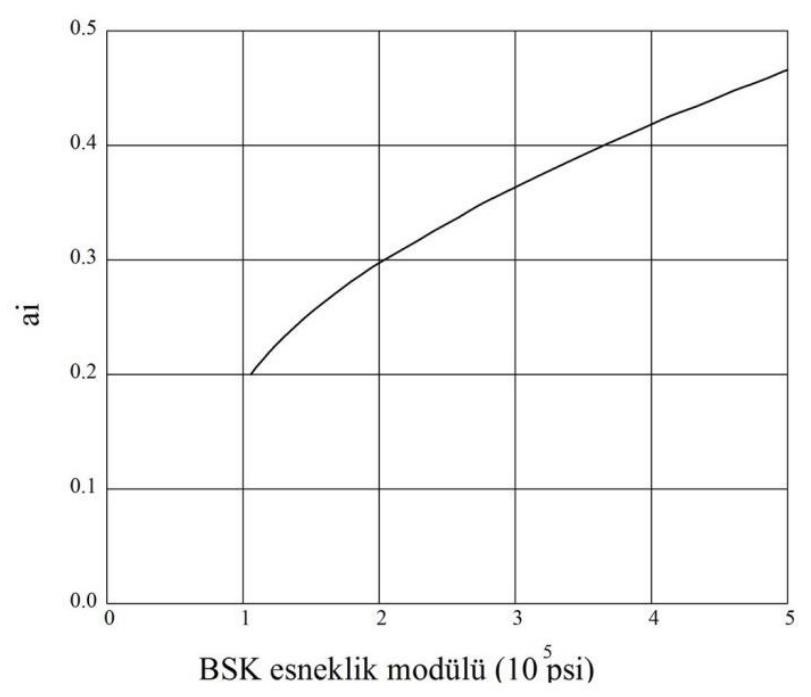

Şekil 2. BSK için izafi mukavemet katsayısı-esneklik modülü dönüşüm grafiği (Huang, 2004)

Analiz kesitlerinin yük altındaki deplasman, gerilme ve birim şekil değiştirme tepkilerini belirlemek için Kenlayer programı kullanılmıştır. Kenlayer, Huang (2004) tarafından geliştirilmiş, Microsoft-Windows tabanl1, esnek ve rijit üstyapıların analizinde kullanılan bir yazılımdır. Kenlayer yazılımında üstyapı tabakaları lineer elastik, non-lineer elastik ve viskoelastik olarak tanımlanabilmekte, tabakalar arası temas, yapışık (bonded) veya bağsiz (unbonded) olarak 
atanabilmektedir. Trafik yükleri ise tekil, dual, dual tandem ve dual tridem olarak belirlenebilmektedir (Muniandy vd., 2013; Ghanizadeh ve Ziaie, 2015; Chegenizadeh vd., 2016). Mevcut çalışmada üstyapı tabakaları lineer elastik olarak tanımlanmış ve tabaka özelliklerini karakterize etmek üzere elastisite modülü ve poisson oranı değerleri kullanılmıştır. Tabakalar arası temas "bonded" olarak belirlenmiştir (Ziari ve Khabiri, 2007; Muniandy vd., 2013; Hafeez vd., 2017).

\section{Bulgular ve tartışma}

Şekil 1'de verilen geleneksel üstyapı kesiti için, BSK, temel ve alttemel tabaka kalınlıkları birbirine eşit ve $20 \mathrm{~cm}$, ve E1 $2393 \mathrm{MPa}$, E2 $232 \mathrm{MPa}, \mathrm{E} 3$ $128 \mathrm{MPa}$ ve $\mathrm{E}_{\text {taban }} 66 \mathrm{MPa}$ olmak üzere yapılan analizlerde elde edilen mekanik tepki değerleri (birim şekil değiştirme) ve buna bağlı olarak hesaplanan $\mathrm{N}_{\mathrm{f}}$ ve $\mathrm{N}_{\mathrm{r}}$ değerleri Tablo 3'te verilmiştir. $\varepsilon_{\mathrm{r}}$ değeri çekme türünde olduğu için eksi işaretli olarak belirtilmiştir.

Tablo 3. Mekanik tepki değerleri ve yol ömrü değerleri

\begin{tabular}{|c|c|c|c|c|c|c|c|c|c|c|}
\hline Er (E-04) & $\varepsilon_{v}(E-04)$ & & $\mathbf{A I}$ & Shell & USACE & BRRC & TRRL & FHWA & ILLINOIS & ARE \\
\hline \multirow[t]{2}{*}{-1.919} & \multirow[t]{2}{*}{3.065} & $\mathbf{N}_{\mathbf{f}}$ & 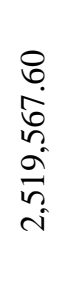 & 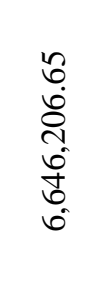 & $\begin{array}{l}\vec{\sigma} \\
\dot{+} \\
\stackrel{+}{0} \\
\infty \\
\stackrel{+}{+} \\
\dot{m}\end{array}$ & 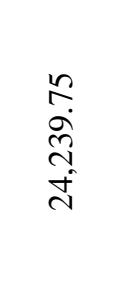 & 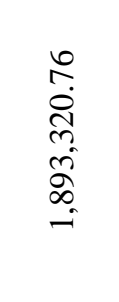 & 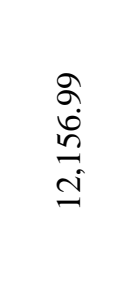 & $\begin{array}{l}0 \\
n \\
0 \\
n \\
n \\
0 \\
0\end{array}$ & 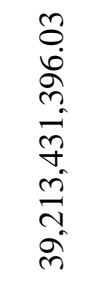 \\
\hline & & $\mathbf{N}_{\mathbf{r}}$ & 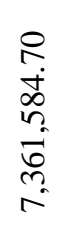 & 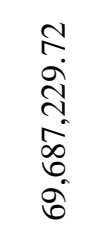 & 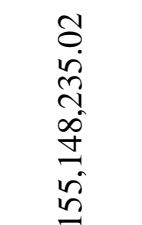 & $\begin{array}{l}\hat{0} \\
\dot{8} \\
\infty \\
\infty \\
0 \\
0 \\
\infty \\
\text { in }\end{array}$ & $\begin{array}{l}\overrightarrow{+} \\
\hat{\sigma} \\
\hat{\sigma} \\
\vec{\sigma} \\
\hat{\sigma} \\
\hat{\sigma}\end{array}$ & ' & ' & ' \\
\hline
\end{tabular}

Tablo 3 incelendiğinde yol ömrü değerlerinin tüm kurumlar için birbirinden önemli ölçüde farklı oldukları görülmektedir. Yorulmaya bağlı yol ömrü değerleri incelendiğinde aynı birim şekil değiştirme değeri için hesaplanan en düşük yol ömrü değeri FHWA'ya ait iken en yüksek yol ömrü değerinin ise ARE'ye ait olduğu görülmektedir. AI, Shell, USACE ve TRRL denklemlerinden elde edilen sonuçlar birbirlerine yakın ve $1.9-6.7 \times 10^{6}$ aralığında değerler almıştır. Sayılan bu yöntemlere ait $\mathrm{N}_{\mathrm{f}}$ değerleri ortalamas1 $3.64 \times 10^{6}$ olarak elde edilmiştir. BRRC ve FHWA denklemlerinden elde edilen sonuçlar sırasıyla bu ortalamanın 0.0067 ve 0.00334 kat altında kalırken ARE denklemi ise bu ortalamanın 10774.94 kat üzerinde sonuç vermiştir. AI, Shell, USACE ve TRRL yöntemlerinden elde edilen değerlerin ortalamaya oranları ise sirasiyla $0.69,1.83,0.96$ ve 0.52 olarak elde edilmiştir. Bu sonuçlara göre ortalamaya en yakın yöntemin USACE olduğu görülmektedir. Tekerlek izine bağlı yol ömrü değerlerinde ise en düşük değer BRRC'ye ait iken en yüksek yol ömrü değeri USACE transfer denkleminden elde edilmiştir. $\mathrm{Nr}$ değerleri arasında $\mathrm{AI}$ ve BRRC denklemlerinden elde edilen sonuçlar birbirilerine yakın nitelikte iken özellikle Shell ve USACE denklemleri diğer yöntemlerin üzerinde sonuçlar vermişlerdir. Aynı kuruma ait $\mathrm{N}_{\mathrm{r}}$ ve $\mathrm{N}_{\mathrm{f}}$ denklemlerinden elde edilen sonuçların birbirlerine oranı Şekil 3'te verilmiştir. Tüm denklemler için tekerlek izine bağlı yol ömrü değerinin yorulmaya bağlı yol ömrü değerinden fazla olduğu açıkça görülmektedir. Buna göre seçilen kesit için yorulmaya bağlı göçmenin, tekerlek izine bağl1 göçmeye nazaran daha kritik olduğu söylenebilir. Şekil 3 incelendiğinde AI, Shell ve TRRL yöntemleri için $\mathrm{N}_{\mathrm{r}} / \mathrm{N}_{\mathrm{f}}$ oranının 2.92-10.49 aralığında olduğu görülmektedir. BRRC yönteminde ise bu oran 241.99'a çıkmaktadır. Bu değer, BRRC yönteminin üstyapı tasarımında esas aldığ yönünde yorumlanabilir.

Değişen H1/H2 ve E1/E2 oranlarına bağlı olarak farklı yöntemlerin $\mathrm{N}_{\mathrm{f}}$ sonuçlarını birbirleri ile kıyaslamak amacıyla, birbirlerine daha yakın sonuçlar verdiği gözlenen AI, Shell, USACE ve TRRL yöntemleri analiz edilmiştir. Yapılan analizde, farklı $\mathrm{H} 1 / \mathrm{H} 2$ ve E1/E2 oranlar1 için yöntemlerden elde edilen $\mathrm{N}_{\mathrm{f}}$ sonuçlarının, referans bir $\mathrm{N}_{\mathrm{f}}$ değerine yaklaşma oranlarının tespit edilmesi amaçlanmıştır. 


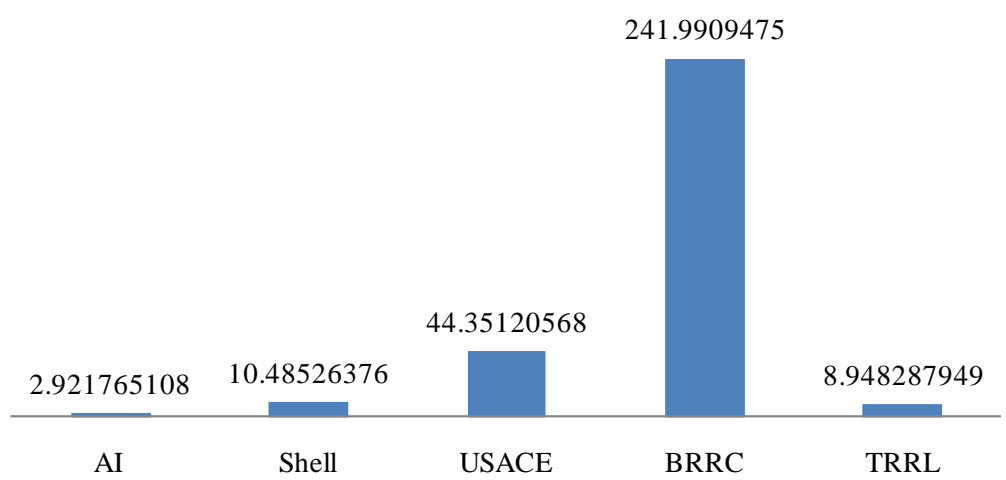

Şekil 3. $\mathrm{N}_{\mathrm{r}} / \mathrm{N}_{\mathrm{f}}$ değerleri

$\mathrm{Bu}$ amaçla herhangi bir H1/H2 ve E1/E2 değeri için en yüksek $\mathrm{N}_{\mathrm{f}}$ değerini veren yöntemin, hesaplanan yol ömrü değeri $\left(\mathrm{N}_{\text {fmax }}\right)$ referans değer olarak seçilmiş, bu referans değer, diğer yöntemlerin yol ömrü değerlerine $\left(\mathrm{N}_{\mathrm{fi}}\right)$ oranlanmış ve $\mathrm{H} 1 / \mathrm{H} 2$ ve E1/E2 değişimine bağlı olarak $\mathrm{N}_{\mathrm{fmax}} / \mathrm{N}_{\mathrm{fi}}$ oran değișimi irdelenmiștir. Tüm $\mathrm{H} 1 / \mathrm{H} 2$ ve E1/E2 değerleri için en yüksek $\mathrm{N}_{\mathrm{f}}$ değerini veren yöntem Shell yöntemi olarak belirlenmiştir. Shell yöntemi sonuçlarını, AI, USACE ve TRRL yöntemlerinden elde edilen sonuçlara bölünmesi ile elde edilen grafikler Şekil 4-6'da verilmiştir.

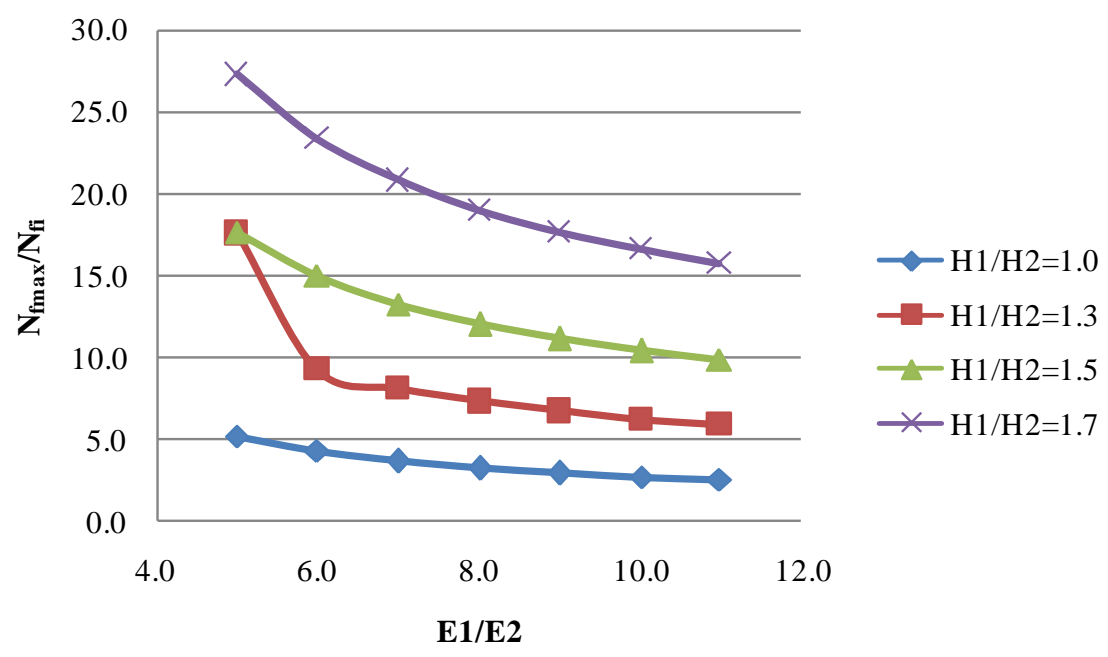

Şekil 4. AI yöntemi için $\mathrm{N}_{\mathrm{fmax}} / \mathrm{N}_{\mathrm{fi}}$ değişimi $\left(\mathrm{E}_{\text {taban }}=66 \mathrm{MPa}\right)$

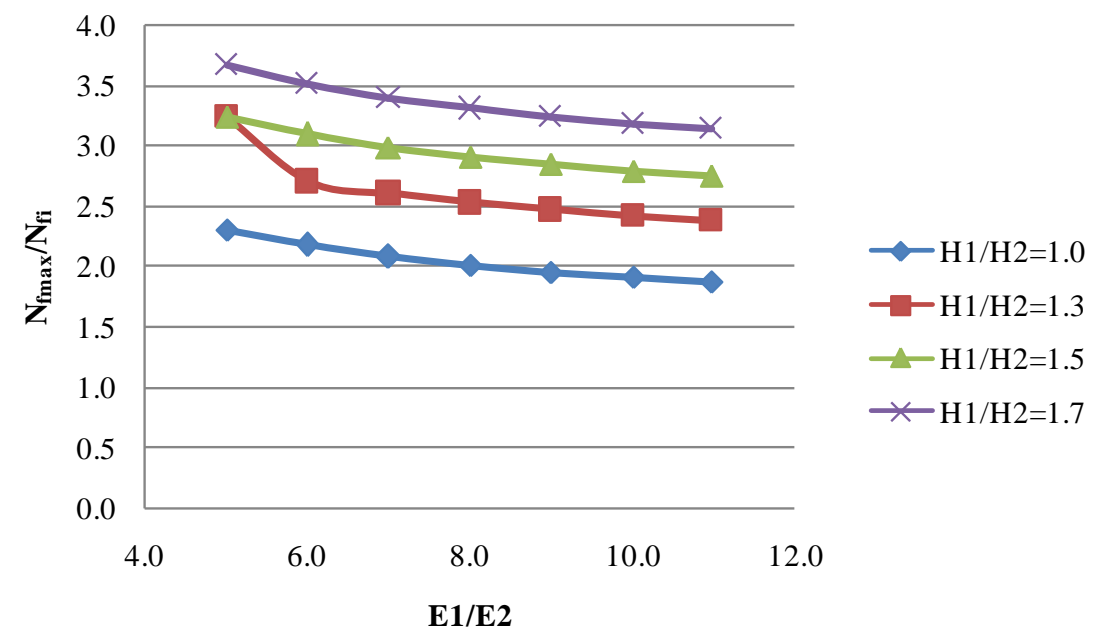

Şekil 5. USACE yöntemi için $\mathrm{N}_{\mathrm{fmax}} / \mathrm{N}_{\mathrm{fi}}$ değişimi $\left(\mathrm{E}_{\text {taban }}=66 \mathrm{MPa}\right)$ 


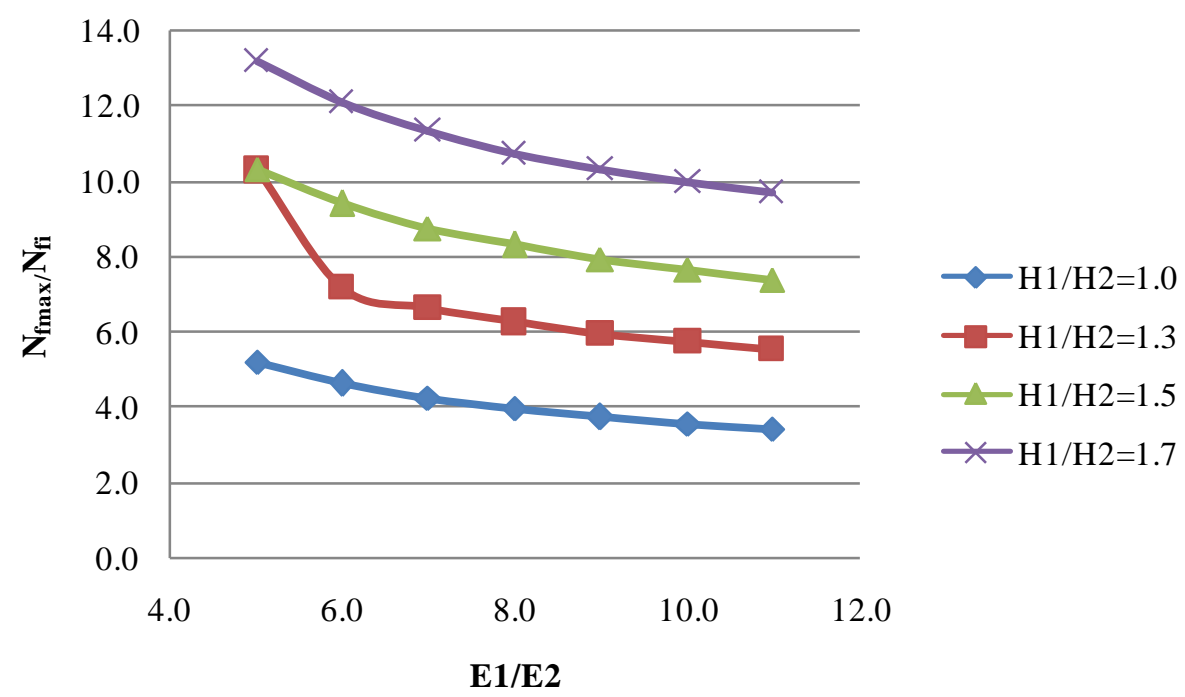

Şekil 6. TRRL yöntemi için $\mathrm{N}_{\mathrm{fmax}} / \mathrm{N}_{\mathrm{fi}}$ değişimi ( $\left.\mathrm{E}_{\text {taban}}=66 \mathrm{MPa}\right)$

Şekil 4-6 incelendiğinde artan E1/E2 oranına bağlı olarak tüm yöntemler için $\mathrm{N}_{\mathrm{fmax}} / \mathrm{N}_{\mathrm{fi}}$ değerlerinin azaldığı görülmektedir. Bir başka deyişle AI, USACE ve TRRL yöntemlerinden elde edilen sonuçlar ile Shell yönteminden elde edilen sonuçlar birbirlerine yaklaşmıştır. $\mathrm{Bu}$ sonuçlar BSK tabakası rijitliğinin temel tabakası rijitliğine oranla artması durumunda M-A yöntemlerin birbirlerine yakın sonuçlar vereceği şeklinde yorumlanabilir. $\mathrm{H} 1 / \mathrm{H} 2$ değişimi göz önüne alındığında ise $\mathrm{H} 1 / \mathrm{H} 2$ değerinin artışına bağlı olarak tüm $\mathrm{N}_{\text {fmax }} / \mathrm{N}_{\mathrm{fi}}$ sonuçlarının arttığı ve yöntemlerin birbirinden uzaklaştığ 1 açıkça görülmektedir. $\quad \mathrm{N}_{\mathrm{fmax}} / \mathrm{N}_{\mathrm{fi}}$ değerleri için en düşük değerler tüm yöntemler için $\mathrm{H} 1 / \mathrm{H} 2$ oran1 1.0 olduğunda elde edilmiştir. $\mathrm{Bu}$ sonuca göre BSK tabakasının kalınlığının temel tabakası kalınlığına oranla artması durumunda MA yöntem sonuçlarının birbirlerinden önemli ölçüde ayrıştıkları net bir şekilde söylenebilir. Özellikle AI yöntemi sonuçları ele alındığında, E1/E2 oran1 5.0 iken, H1/H2 oranının 1.7 olmas1 durumunda Shell yöntemi AI yönteminden 27.3 kat daha yüksek sonuç vermektedir. Hâlbuki $\mathrm{H} 1 / \mathrm{H} 2$ değerinin 1.0 olması durumunda bu oran ayn1 E1/E2 değeri için 5.3 olarak belirlenmiştir. Analiz edilen üç yöntemin Shell yöntemi sonuçlarına yakınlığı analiz edildiğinde USACE yönteminin tüm $\mathrm{E} 1 / \mathrm{E} 2$ ve $\mathrm{H} 1 / \mathrm{H} 2$ oranları için en yakın sonuçları veren yöntem olduğu görülmektedir. Çalış1lan tüm kesitler için USACE yöntemine ait $\mathrm{N}_{\text {fmax }} / \mathrm{N}_{\mathrm{fi}}$ değeri en fazla 3.7 olarak tespit edilmiştir. $\mathrm{Bu}$ oran anılan bu iki yöntemin birbirlerine oldukça yakın sonuçlar verdiğini ifade etmektedir. AI yöntemi ise aynı şekilde tüm E1/E2 ve $\mathrm{H} 1 / \mathrm{H} 2$ oranları için Shell yönteminden en fazla uzaklaşan yöntem olarak belirtilebilir.

Birbirlerine çok yakın sonuçlar verdiği belirlenen Shell ve USACE yöntemlerinin taban zemini rijitliği değişimine bağlı olarak $\mathrm{N}_{\mathrm{fmax}} / \mathrm{N}_{\mathrm{fi}}$ değerleri hesaplanarak Tablo 4 'te verilmiştir.

Tablo 4 incelendiğinde taban zemini rijitliğinin tüm değerleri için $\mathrm{N}_{\text {fmax }} / \mathrm{N}_{\text {fi }}$ değerlerinin önemli ölçüde aynı kaldığ 1 ve değişmediği gözlenmiştir. Hesaplanan 84 değerden sadece 17 tanesinde değişim gözlenirken bu değişimin de anlamlı olmadığı tablodan açıkça gözlenebilmektedir.

$\mathrm{N}_{\mathrm{f}}$ sonuçlarının değerlendirilmesinde olduğu gibi, değişen $\mathrm{H} 1 / \mathrm{H} 2$ ve E1/E2 oranlarına bağlı olarak farklı yöntemlerin $\mathrm{N}_{\mathrm{r}}$ sonuçlarını birbirleri ile kıyaslamak amacıyla, en yükssek $\mathrm{N}_{\mathrm{r}}$ değerini veren yöntemin, hesaplanan yol ömrü değeri $\left(\mathrm{N}_{\mathrm{rmax}}\right)$ referans değer olarak seçilmiş, bu referans değer, diğer yöntemlerin yol ömrü değerlerine $\left(\mathrm{N}_{\mathrm{ri}}\right)$ oranlanmış ve $\mathrm{N}_{\mathrm{rmax}} / \mathrm{N}_{\mathrm{ri}}$ değişim grafikleri çizilmiş̧ir. Tüm $\mathrm{H} 1 / \mathrm{H} 2$ ve E1/E2 değerleri için en yüksek $\mathrm{N}_{\mathrm{r}}$ değerini veren yöntem USACE yöntemi olarak belirlenmiştir. Bu sebeple USACE yöntemi sonuçlarının, AI, Shell, BRRC ve TRRL yöntemlerinden elde edilen sonuçlara bölünmesi ile elde edilen grafikler Şekil 7-10'da verilmiştir. 
Tablo 4. Taban zemini rijitlik değişimine bağlı olarak $\mathrm{N}_{\mathrm{fmax}} / \mathrm{N}_{\mathrm{fi}}$ değişimi

\begin{tabular}{|c|c|c|c|c|}
\hline E1/E2 & H1/H2 & $E_{\text {taban }}=66 \mathrm{MPa}$ & $\mathrm{E}_{\text {taban }}=87 \mathrm{MPa}$ & $\mathrm{E}_{\text {taban }}=110 \mathrm{MPa}$ \\
\hline 5.0 & \multirow{7}{*}{1.0} & 2.3 & 2.3 & 2.3 \\
\hline 6.0 & & 2.2 & 2.2 & 2.2 \\
\hline 7.0 & & 2.1 & 2.1 & 2.1 \\
\hline 8.0 & & 2.0 & 2.0 & 2.0 \\
\hline 9.0 & & 2.0 & 2.0 & 2.0 \\
\hline 10.0 & & 1.9 & 1.9 & 1.9 \\
\hline 11.0 & & 1.9 & 1.9 & 1.9 \\
\hline 5.0 & \multirow{7}{*}{1.3} & 3.2 & 3.3 & 3.3 \\
\hline 6.0 & & 2.7 & 2.7 & 2.8 \\
\hline 7.0 & & 2.6 & 2.6 & 2.7 \\
\hline 8.0 & & 2.5 & 2.6 & 2.6 \\
\hline 9.0 & & 2.5 & 2.5 & 2.5 \\
\hline 10.0 & & 2.4 & 2.5 & 2.5 \\
\hline 11.0 & & 2.4 & 2.4 & 2.4 \\
\hline 5.0 & \multirow{7}{*}{1.5} & 3.2 & 3.3 & 3.3 \\
\hline 6.0 & & 3.1 & 3.1 & 3.2 \\
\hline 7.0 & & 3.0 & 3.0 & 3.1 \\
\hline 8.0 & & 2.9 & 3.0 & 3.0 \\
\hline 9.0 & & 2.9 & 2.9 & 2.9 \\
\hline 10.0 & & 2.8 & 2.8 & 2.9 \\
\hline 11.0 & & 2.8 & 2.8 & 2.8 \\
\hline 5.0 & \multirow{7}{*}{1.7} & 3.7 & 3.7 & 3.8 \\
\hline 6.0 & & 3.5 & 3.6 & 3.6 \\
\hline 7.0 & & 3.4 & 3.5 & 3.5 \\
\hline 8.0 & & 3.3 & 3.4 & 3.4 \\
\hline 9.0 & & 3.2 & 3.3 & 3.3 \\
\hline 10.0 & & 3.2 & 3.2 & 3.3 \\
\hline 11.0 & & 3.1 & 3.2 & 3.2 \\
\hline
\end{tabular}

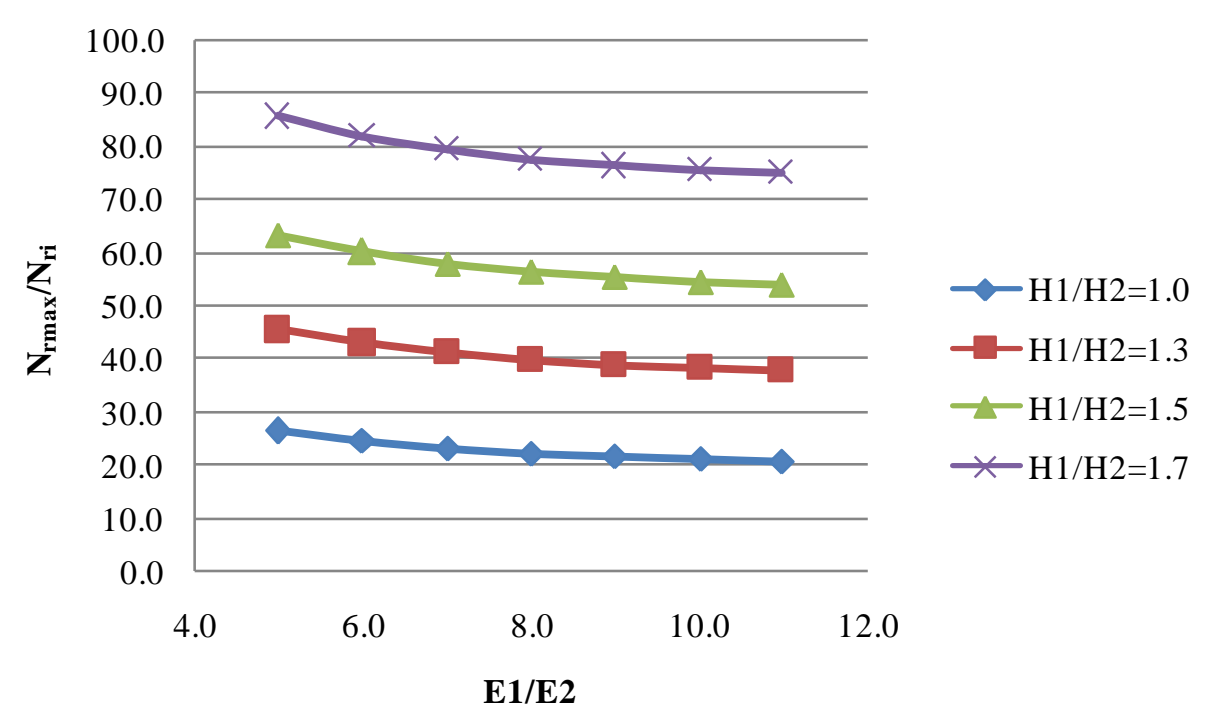

Şekil 7. AI yöntemi için $\mathrm{N}_{\mathrm{rmax}} / \mathrm{N}_{\mathrm{ri}}$ değişimi $\left(\mathrm{E}_{\text {taban }}=66 \mathrm{MPa}\right)$ 


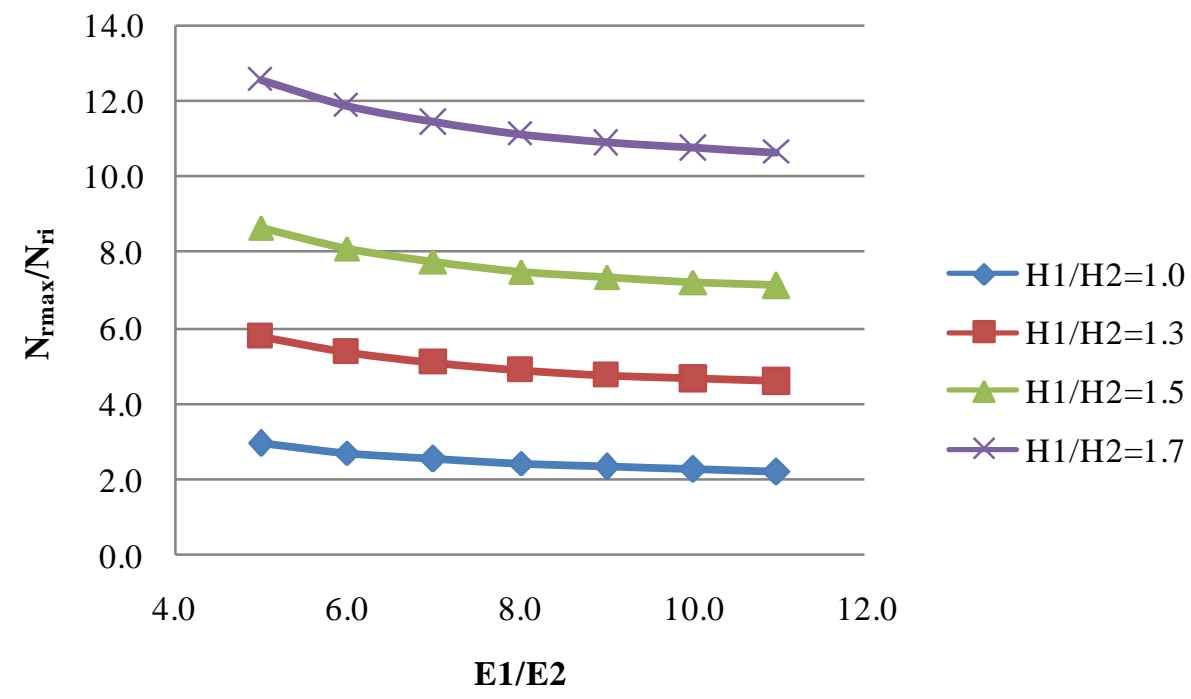

Şekil 8. Shell yöntemi için $\mathrm{N}_{\mathrm{rmax}} / \mathrm{N}_{\mathrm{ri}}$ değişimi $\left(\mathrm{E}_{\text {taban }}=66 \mathrm{MPa}\right)$

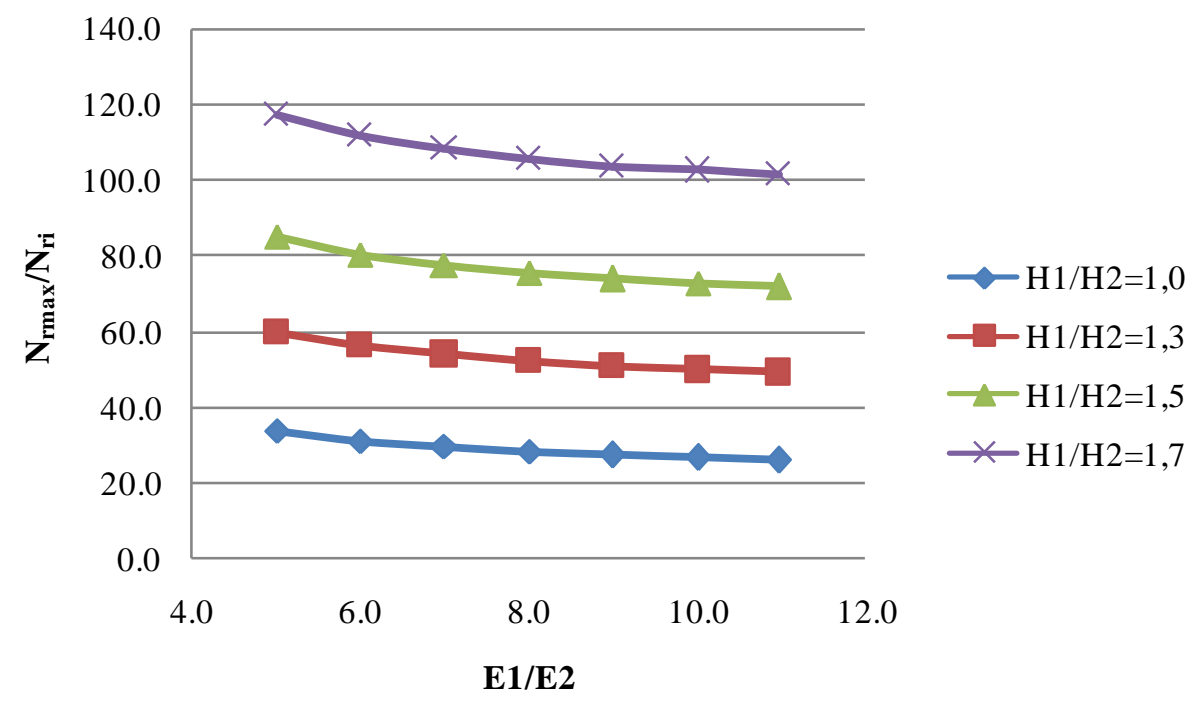

Şekil 9. BRRC yöntemi için $\mathrm{N}_{\mathrm{rmax}} / \mathrm{N}_{\mathrm{ri}}$ değişimi $\left(\mathrm{E}_{\text {taban }}=66 \mathrm{MPa}\right)$

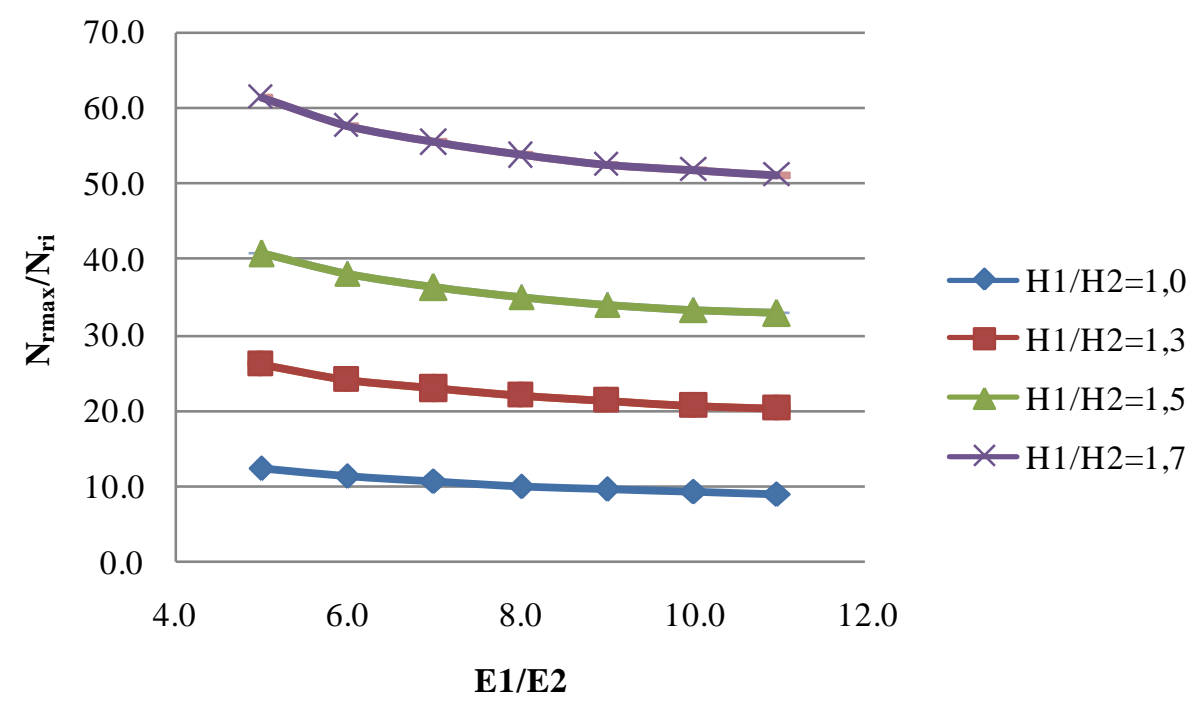

Şekil 10. TRRL yöntemi için $\mathrm{N}_{\mathrm{rmax}} / \mathrm{N}_{\mathrm{ri}}$ değiş̧imi ( $\left.\mathrm{E}_{\text {taban }}=66 \mathrm{MPa}\right)$ 
Şekil 7-10 incelendiğinde referans alınan USACE yöntemi ile en yakın sonuçları veren yöntemin Shell yöntemi olduğu açıkça görülmektedir. H1/H2'nin 1.0 ve E1/E2'nin 11.0 değeri için $\mathrm{N}_{\mathrm{rmax}} / \mathrm{N}_{\mathrm{ri}}$ değeri Shell yöntemi için 2.2'ye düşmüştür. Analizi yapılan yöntemler arasında, referans yönteme en uzak sonuçları veren yöntem ise BRRC yöntemidir. H1/H2'nin 1.7 ve E1/E2'nin 5.0 değeri için $\mathrm{N}_{\text {rmax }} / \mathrm{N}_{\text {ri }}$ değeri BRRC yöntemi için 117.5 olarak hesaplanmıştır.

E1/E2 oran1 değişiminin, referans yöntem sonucuna yaklaşmadaki etkinliği dikkate alındığında artan E1/E2 oranı için tüm yöntemlerde $\mathrm{N}_{\mathrm{rmax}} / \mathrm{N}_{\mathrm{ri}}$ değerinin düştüğü görülmektedir. Buna göre temel tabakası rijitliği BSK tabakasına oranla azaldığında M-A yöntem sonuçlarının birbirleri ile daha uyumlu olduğu sonucuna var1labilir. H1/H2 değişimi dikkate alındığında ise artan $\mathrm{H} 1 / \mathrm{H} 2$ değerine bağli olarak $\mathrm{N}_{\mathrm{rmax}} / \mathrm{N}_{\mathrm{ri}}$ değerinin yükseldiği, bir başka deyişle yöntem sonuçlarının birbirlerinden ayrıştı̆̆ 1 net bir şekilde gözlenmektedir.

Çalı̧̧mada analiz edilen M-A modellerin, yorulma ve tekerlek izine bağlı yol ömrü hesaplamalarında önemli ölçüde etkili olduğu belirlenen kalınlık oranı değişimine duyarlılıklarını test etmek amaciyla, E1/E2 değeri 11.0 olarak sabit tutulurken $\mathrm{H} 1 / \mathrm{H} 2$ değerinin 1.0'dan 1.7'ye çıkmas1 durumunda $\mathrm{N}_{\text {fmax }} / \mathrm{N}_{\mathrm{fi}}$ ve $\mathrm{N}_{\mathrm{rmax}} / \mathrm{N}_{\mathrm{ri}}$ değerlerinin kaç kat arttı̆̆ 1 belirlenmiş ve sonuçlar Şekil 11'de verilmiştir.

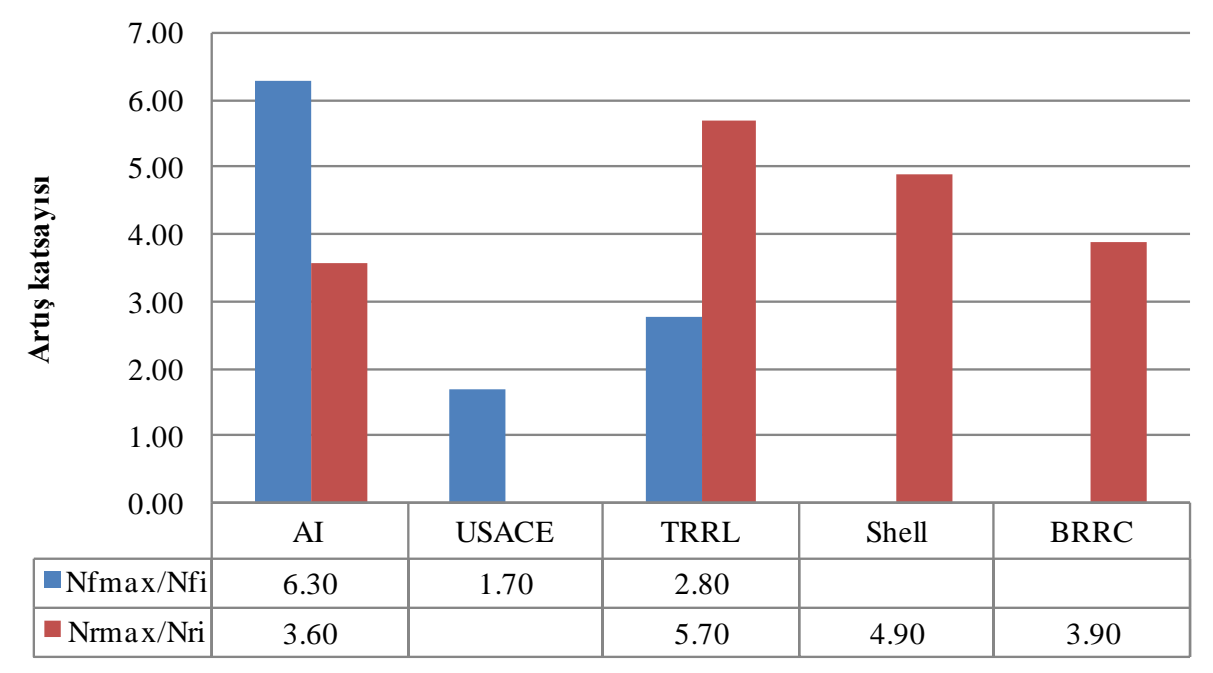

Şekil 11. H1/H2 oranına bağlı $\mathrm{N}_{\text {fmax }} / \mathrm{N}_{\mathrm{fi}}$ ve $\mathrm{N}_{\mathrm{rmax}} / \mathrm{N}_{\mathrm{ri}}$ artış katsayıları

Şekil 11 incelendiğinde yorulma modelleri arasında AI modelinin, tekerlek izi modelleri arasında ise TRRL yönteminin kalınlık oranı değişimine en duyarlı modeller oldukları belirtilebilir. Temel tabakası kalınlığı sabit iken BSK tabakası kalınlığının artması sonucunda referans modele göre en az duyarlılık gösteren modelin ise sadece \%1.7'lik bir değişim gösteren USACE'nin yorulma modeli olduğu gözlenmiştir.

\section{Sonuçlar ve öneriler}

Geleneksel bir esnek üstyapı kesitinin BSK ve temel tabakalarının değişen kalınlık ve rijitlik oranlarına göre M-A modeller ile analiz edildiği ve model sonuçlarının kıyaslandığı bu çalışmadan elde edilen sonuçlar aşağıdaki gibi sıralanabilir;

- M-A esnek üstyapı tasarım yöntemlerinde kullanılan ampirik transfer denklemlerinin, elde edilen yol ömrü değerleri üzerinde oldukça etkin bir rol oynadığı açıkça görülmektedir. $\mathrm{Bu}$ durum, ampirik denklemlerin ortaya çıarılmasında uygulanan deney kesitlerinin, yükleme durumunun, kaplama malzemelerinin ve çevresel koşulların birbirlerinden oldukça farklı ve ilgili kesit ve coğrafi bölgeye özel olduğu sonucunu doğurmaktadır. Bu anlamda, esnek üstyapı tasarımında M-A yöntem tercih edilmesi durumunda kullanılacak modelin iyi analiz edilmesi ve tasarımı yapılacak yol ile uyumunun sağlanması kritiktir.

- Esnek üstyapı tasarımında yolun öncül göçme tipinin belirlenmesi de önemli bir husus olarak dikkate alınmalıdır. Mevcut çalışmada yapılan analizler, tüm kurumlar için tekerlek izine bağl1 yol ömrünün yorulmaya bağlı yol ömründen daha fazla olduğunu 
göstermektedir. Bu sonuca göre, tekerlek izine göre tasarlanan bir yol ağır trafik yüküne maruz kaldığında yorulmaya bağlı ve daha kısa sürede deforme olabilir. Aynı şekilde hafif trafiğe maruz bir yol yorulmaya bağlı analiz edildiğinde gereğinden daha kalın bir kesit imalatı yapılarak kaynak israfı söz konusu olabilir.

- M-A yöntemlerin ampirik transfer modelleri analiz edildiğinde E1/E2 oranı artışına bağlı olarak farklı kurumlara ait modellerin birbirlerine yakın sonuçlar verdiği, H1/H2 oranı arttığında ise sonuçların birbirlerinden uzaklaştığı tespit edilmiştir. Bu durum, BSK tabakası rijitliğinin artması ve yükün esas olarak kaplama tarafından taşınması durumunda modellerin birbirlerine yakın sonuçlar vermesi şeklinde de ifade edilebilir. Buna göre ampirik transfer model sonuçlarını birbirlerinden ayrıştıran ana etkenin alt tabakalarda kullanılan ve yüke bağlı nonlineer davranış sergilemesi muhtemel granüler tabakalar olduğu sonucuna varılabilir.

- Farklı kurumlara ait transfer denklemleri analiz edildiğinde hem yorulma hem de tekerlek izine bağlı modeller arasında USACE ve Shell yöntemlerinin birbirleri ile uyumlu sonuçlar verdiği belirlenmiştir. Özellikle tekerlek izine bağlı analizlerde birbirlerine yakın sonuçlar veren modellerin ortalaması alınarak bu ortalamaya yakınlık analizi yapıldığında USACE yönteminin ortalamaya en yakın ve en tutarlı model olduğu belirtilebilir.

- $\quad$ H1/H2 değişiminin sonuçlar üzerindeki etkisi dikkate alındığında, bu değişime en duyarlı iki yöntemin yorulma modelleri arasında AI modeli, tekerlek izi modelleri arasında TRRL modeli olduğu tespit edilmiştir. Bu modeller ile yapılan M-A tasarımlarda BSK ve temel tabakaları arasındaki orana azami ölçüde dikkat edilmesi ve bir tasarım parametresi olarak ele alınması bu çalışmanın önemli bir sonucu olarak ortaya koyulabilir.

\section{Semboller}

$\left(\varepsilon_{r}\right) \quad$ : Yatay çekme birim şekil değiştirmeleri

( $\left.\varepsilon_{v}\right) \quad$ : Düşey basinç birim şekil değiştirmeleri

$\left(N_{f}\right) \quad$ : Yorulmaya bağlı bozulma için gerekli yük tekrar sayls

$\left(N_{r}\right) \quad$ : Tekerlek izine bağll bozulma için gerekli yük tekrar sayısı

$\left(E_{\text {yüzey }}\right)$ : Yüzey tabakası elastisite modülü

(v) : Poisson oranı

$\left(E_{\text {temel }}\right)$ : Temel tabakasl elastisite modülü

(Ealtemel): Alttemel tabakası elastisite modülü

$\left(a_{\text {temel }}\right)$ : Temel tabakast izafi mukavemet katsayısı

$\left(a_{\text {alttemel }}\right)$ : Alttemel tabakast izafi mukavemet katsayisı

$\left(E_{\text {taban }}\right)$ : Taban zemini elastisite modülü

(H) : Tabaka kalınlığ

(CR) : Temas yarıçapı

\section{Kaynaklar}

Abd Alla, E. M., (2006). The rational use of finite element method in the analysis of flexible pavements. Journal of Engineering Sciences, 34(4), 1185-1211.

Adhikari, S., Shen, S. and You, Z., (2009). Evaluation of fatigue models of hot-mix asphalt through laboratory testing. Transportation Research Record, 2127, 36-42. https://doi.org/10.3141/2127-05.

Aguib, A. A., (2013). Flexible pavement design aashto 1993 versus mechanistic-empirical pavement design. Master of Science, The American University in Cairo, School of Sciences and Engineering. Cairo.

Ahmed, A. and Erlingsson, S., (2016). Viscoelastic response modelling of a pavement under moving load. Transportation Research Procedia, 14, 748-757.

http://dx.doi.org/10.1016/j.trpro.2016.05.343

Behiry, A. E. A. E. M., (2012). Fatigue and rutting lives in flexible pavement. Ain Shams Engineering Journal, 3(4), 367-374. http://dx.doi.org/10.1016/j.asej.2012.04.008

Carvalho, R. L. and Schwartz, C. W., (2006). Comparisons of flexible pavement designs: AASHTO empirical versus NCHRP project 137A mechanistic-empirical. Transportation Research Record, 1947, 167-174.

Chegenizadeh, A., Keramatikerman, M. and Nikraz, H., (2016). Flexible pavement modelling using Kenlayer. Electronic Journal of Geotechnical Engineering, 21(7), 2467-2479. 
Chen, Y., (2009). Viscoelastic modeling of flexible pavement. Doctor of Philosophy, The Graduate Faculty of The University of Akron. Ohio.

Ekwulo, E. O. and Eme, D. B., (2009). Fatigue and rutting strain analysis of flexible pavements designed using CBR methods. African Journal of Environmental Science and Technology, 3(12), 412-421.

https://doi.org/10.1080/14680629.2007.9690094

Ekwulo, E. O. and Eme, D. B., (2013). Expected traffic, pavement thickness, fatigue and rutting strain relationship for low volume asphalt pavement. The International Journal of Engineering and Science (IJES), 2(8), 62-77.

Ghanizadeh, A. R. and Ziaie, A., (2015). NonPAS: A program for nonlinear analysis of flexible pavements. International Journal of Integrated Engineering, 7(1), 21-28.

Hadi, M. N. S. and Bodhinayake, B. C., (2003). Nonlinear finite element analysis of flexible pavements. Advances in Engineering Software, 34(11-12), 657-662.

Hafeez, I., Shan, A., Ali, A. and Ahmed, I., (2017). Flexible pavement design evaluation using mechanistic-empirical approaches. Technical Journal, University of Engineering and Technology 22(2), 27-33.

Huang, Y. H., (2004). Pavement Analysis and Design (2nd ed.). New Jersey: Pearson Prentice Hall.

Lu, M. P. C. P., Bratlien, A. and Tolliver, D., (2014). Understanding mechanistic-empirical pavement design guide (MEPDG) for North Dakota implementation. Upper Great Plains Transportation Institute North Dakota State University. Erişim adresi, https://www.ugpti.org/resources/reports/downlo ads/mpc14-274.pdf

Mashayekhi, M., Amini, A. A., Behbahani, H. and Nobakht, S., (2011). Comparison of mechanisticempirical and empirical flexible pavement design procedures of AASHTO: A Case study. 5th International Conference Bituminous Mixtures and Pavements (pp. 319-328). Thessaloniki, Greece.

Mokhtari, A. and Nejad, F., (2012). Mechanistic approach for fiber and polymer modified SMA mixtures. Construction and Building Materials, 36, 381-390.

Mousa, M. R., Abo-Hashema, M. A., Gadallah, A. A. and Mousa, R. M., (2015). Evaluation of pavement performance prediction models under different traffic and climatic conditions. 14th International Conference on Asphalt, Pavement Engineering, and Infrastructure (pp.1-19).
Muniandy, R., Eltaher, A. and Thamer, N., (2013). Comparison of flexible pavement performance using Kenlayer and Chev PC software program. Australian Journal of Basic and Applied Sciences, 7(9), 112-119.

Sağlık, A. ve Güngör, A. G., (2008). Esnek üstyapılar projelendirme rehberi: Ankara, Karayolları Genel Müdürlüğü, 148 p (in Turkish).

Sarkar, A., (2016). Numerical comparison of flexible pavement dynamic response under different axles. International Journal of Pavement Engineering, 17(5), 377-387. http://dx.doi.org/10.1080/10298436.2014.99319 5

Tunç, A., (2004). Kaplama mühendisliği ve uygulamaları. Ankara: Asil Yayın Dağıtım.

Tunç, A., (2007). Yol malzemeleri ve uygulamalar (2.Bask1). Ankara: Nobel Yayınevi.

Yoo, P. J., Al-Qadi, I. L., Elseifi, M. A. and Janajreh, I., (2006). Flexible pavement responses to different loading amplitudes considering layer interface condition and lateral shear forces. International Journal of Pavement Engineering, 7(1), 73-86. https://doi.org/10.1080/10298430500516074

Ziari, H. and Khabiri, M. M., (2007). Interface condition influence on prediction of flexible pavement life. Journal of Civil Engineering and Management, 13(1), 71-76. https://doi.org/10.1080/13923730.2007.9636421 